\title{
Enzymes associated with anti-inflammatory potentialities of purified terpenoid extracts from the selected sea weeds
}

\author{
Research Article
}

\section{Sumayya SS1, Lubaina AS², Murugan $\mathbf{K}^{3 *}$}

\author{
1. Assistant Professor, Department of Botany, SNGS College, Pattambi, Palakkad, Kerala. \\ 2. Assistant Professor, Department of Botany, Christian College, Kattakada. \\ 3. Director, CISSA, Trivandrum, Kerala, India.
}

\begin{abstract}
Introduction: Macrophages are phagocytic WBCs involved in the immune defense and will be activated during inflammatory disorders. The synthesis of cytokines and mediators, particularly nitric oxide (NO) is triggered by the macrophage activator. NO induces many biological events. Therefore, NO regulation is proven to be potential for exploring anti-inflammatory drugs. Aim: The anti-inflammatory action of the purified terpenoid extracts from red algae such as Hypnea musciformis, Gracilaria dura and Kappaphycus alvarezii on LPS induced RAW 264.7 macrophages on lipoxygenase, cyclooxygenase, hyaluronidase, xanthine oxidase and myeloperoxidase inhibitory effects were evaluated. Methods: The methanolic extract of the sea weeds were subjected to silica gel column chromatography and the fraction was further subjected to GC-MS analysis. Then, the potentiality of the purified terpenoid extracts to inhibit various inflammation causing enzymes such as COX, LOX, hyaluronidase, xanthineoxidase and myeloperoxidase were carried out. Findings: The terpenoid extracts reduced the enzyme activities in a dose dependent manner as compared to control group. The extracts inhibited xanthine oxidase activity effectively at $250 \mu \mathrm{g} / \mathrm{ml}$ i.e., a maximum inhibitory activity of $62.1 \%$ as compared to the standard drug, allopurinol. The extract significantly inhibited lipoxygenase activity, with highest inhibitory activity at $100 \mu \mathrm{g} / \mathrm{ml}$. The nitric acid synthesis was reduced to $8.5 \mu \mathrm{M}$ by Hypnea musciformis. Conclusion: The present study revealed that the purified terpenoid extracts from $H$. musciformis exhibited potent anti-inflammatory activities followed by $G$. dura and $K$. alvarezii via regulating the anti-inflammatory enzymes. These findings provide justification for the traditional use of the red algae in inflammatory conditions.
\end{abstract}

Key Words: Red algae, Inflammation, Nitric oxide inhibition, Terpenoids, Cytokine mediators, Enzymes.

\section{Introduction}

Seaweeds are inbuilt with unique physiological and biochemical systems against adverse environmental conditions to combat life. From ancient time onwards Asian and European countries used the seaweeds as a source of polysaccharides for food and pharmaceutical uses. Currently, the seaweeds are proven to be a rich source of potent bioactive compounds that has immense importance in human life. Primary and secondary metabolites produced by seaweeds are of great interest. The secondary metabolites synthesized by seaweeds demonstrate a broad spectrum of bioactivities varying from neurological issues in humans to algicidal, nematicidal, insecticidal etc (1). Seaweeds are the source of amino acids, terpenoids, phlorotannins, steroids,

\section{* Corresponding Author:}

\section{Murugan K}

Director,

CISSA,

Trivandrum,

Kerala. India

Email Id: harimurukan@gmail.com phenolic compounds, halogenated ketones and alkanes and cyclic polysulphides. Currently, there is an increased interest in phyto products with valuable medicinal properties such as terpenoids. Epidemiological and experimental studies suggest that terpenoids from seaweeds may be helpful in the prevention and therapy of cancers and prostate inflammatory disorders. Seaweeds also have the valuable medicinal components such as antibiotics, laxatives, anticoagulants, antiulcer products and suspending agents in radiological preparations. Fresh and dry seaweeds are extensively consumed by people especially living in the coastal areas. From the literature, it is observed that the edible seaweeds contain a significant amount of the protein, vitamins, enzymes and minerals essential for the human nutrition (2). The defensive strategy of many of the red algal species suggests that they possess many anti-oxidative and anti-genotoxic constituents in their cells. For this reason, interest in marine algae as a promising potential source of pharmaceutical agents has increased during the last few years. Similarly, seaweed possess wet, softening properties which according to traditional Chinese medicine enables them to dissolve hard nodules and tumors and to reduce swelling of the thyroid and lymph glands. Seaweed helps decongest swollen or 
inflamed lymph nodes; it can be consumed as the treatment for auto-immune illnesses, including chronic fatigue, HIV, arthritis and chronic allergies (3). In this juncture, the present study was designed to evaluate the anti-inflammatory action of the purified terpenoid extracts from red algae such as Hypnea musciformis, Gracilaria dura and Kappaphycus alvarezii on LPS induced RAW 264.7 macrophages on lipoxygenase, cyclooxygenase, hyaluronidase, xanthine oxidase and myeloperoxidase inhibitory effects.

\section{Materials and Methods \\ Plant materials}

The marine algae Hypnea musciformis, Gracilaria dura and Kappaphycus alvarezii were collected during March 2018, from the Mandapam coast (latitude $9^{\circ} 17^{\prime} \mathrm{N}$, longitude $79^{\circ} 22^{\prime} \mathrm{E}$ ), Gulf of Mannar. Specimens for all the three sea weeds were collected, dried, properly identified and authenticated with the reference from CMFRI, Mandapam, Tamil nadu. Then $50 \mathrm{~g}$ washed samples were powdered and subjected to Soxhlet extraction with $250 \mathrm{ml}$ of methanol. The extraction was repeated thrice. The crude extract was then filtered and kept at room temperature for evaporation. Fractionation of each sample was done by silica gel column chromatography (CC) using different ratios of petroleum ether and ethyl acetate as solvent combinations for each algal extract. The purified fractions obtained was collected and then quantified for the presence of terpenoids and further determined by GC-MS.

\section{GC-MS analysis}

For GC-MS analysis, the purified sample was injected into a HP-5 column $(30 \mathrm{~m} \mathrm{X} 0.25 \mathrm{~mm}$ i.d with 0.25 ì film thickness), Agilent technologies $6890 \mathrm{~N}$ JEOL GC Mate II GC-MS model. Helium was used as carrier gas with a flow rate of $1 \mathrm{~mL} / \mathrm{min}$; the injector was operated at $200^{\circ} \mathrm{C}$ and column oven temperature was programmed as 50 $-250^{\circ} \mathrm{C}$ at a rate of $10^{\circ} \mathrm{C} / \mathrm{min}$ injection mode. A chromatogram was obtained and the mass spectrum of the unknown component was compared with the spectrum of the known components stored in the NIST library (4).

\section{Enzyme inhibitory activity \\ 5-lipoxygenase (LOX) inhibitory assay}

5-LOX inhibitory activity of purified terpenoid extracts from $H$. musciformis, G. dura and $K$. alvarezii was determined by the spectrometric method (5). OD was measured at $\lambda=234 \mathrm{~nm}$ for 10 min. Percentage inhibition of 5-LOX was determined by comparison of reaction rates of the extracts relative to control using the formula $(E-S) / E \times 100$, where $\mathrm{E}$ and $\mathrm{S}$ were the activities of the enzyme with and without extracts, respectively. $\mathrm{IC}_{50}$ values were determined. Indomethacin was used as the reference standard.

\section{Assay for cyclooxygenase (COX) inhibition}

The COX inhibitor screening assay directly measures PGF $2 \alpha$ by stannous chloride reduction of COX-derived PGH2 produced in the COX reaction (6). The reaction system consists of reaction buffer, haem, enzyme and plant extract pre-incubated at $37^{\circ} \mathrm{C}$ for twenty minutes with background and enzyme controls. The absorbance was read at 420 $\mathrm{nm}$. The data was plotted as \% B/B0 (Standard Bound / Maximum Bound) versus log concentration using a 4-parameter logistic curve fit. The concentration of each sample was determined from a standard curve with appropriate dilutions and used to calculate the percent inhibition as per the formula given below:

\section{Percent Inhibition $(\%)=($ Activity of Control - Activity of Test) x $100 /$ Activity of Control}

The percentage inhibition was plotted against the inhibitor concentration to determine the $\mathrm{IC}_{50}$ value (concentration at which there was $50 \%$ inhibition).

\section{Hyaluronidase (HA) inhibitory assay}

Hyaluronidase inhibitory activity of purified terpenoid extracts from $H$. musciformis, G. dura and $K$. alvarezii was evaluated by a spectrometric method with slight modifications (7). Extracts were assayed at the concentrations of 100 to $500 \mu \mathrm{g} / \mathrm{mL}$. Absorbance was measured at $\lambda=585 \mathrm{~nm}$. Percentage enzyme inhibition was calculated as compared to the control. Tannic acid was used as the reference standard.

\section{Xanthine oxidase (XO) inhibitory activity}

Xanthine oxidase inhibitory activity of purified terpenoid extracts from $H$. musciformis, $G$. dura and $K$. alvarezii was determined by a kinetic method (8). Extracts were tested at the assay concentration of $50-250 \mu \mathrm{g} / \mathrm{ml}$. Absorbance was monitored with the change of absorbance at $\lambda=295$ $\mathrm{nm}$ for $15 \mathrm{~min}$. Percentage inhibition of xanthine oxidase was calculated using the formula $(E-S) / E \times$ 100 , where $E$ is the activity of enzyme without extracts and $\mathrm{S}$ is the activity of enzyme with extracts. Allopurinol was used as the reference standard.

\section{Viability assay of LPS-activated RAW 264.7 macrophages}

Murine macrophage (RAW 264.7) cells were cultured and maintained in DMEM supplemented with standard antibiotics and other standardized parameters. The plated cells were treated with different concentrations of the terpenoid extracts from the selected red algae $(100-500 \mu \mathrm{g} / \mathrm{mL})$ and incubated for $30 \mathrm{~min}$ (humidified atmosphere, 5\% $\mathrm{CO}_{2}, 37^{\circ} \mathrm{C}$ ), followed by the incubation with bacterial lipopolysaccharide (LPS, $1 \mu \mathrm{g} / \mathrm{ml}$ ) for $24 \mathrm{~h}$ (9). 


\section{Nitric oxide (NO) assay}

The inhibition of nitric oxide production was determined using the Griess assay (9) and absorbance was measured at $\lambda=540 \mathrm{~nm}$. The nitrite concentration was determined using a standard curve of sodium nitrite $(\mathrm{y}=0.012 \times+0.036, \mathrm{R} 2=0.999)$. Percentage inhibition of nitric oxide formation by extracts was also calculated (10).

\section{Myeloperoxidase (MPO) assay}

Myeloperoxidase (MPO) activity was assayed as per the protocol (11). The change in absorbance at $460 \mathrm{~nm}$ was measured. MPO activity was presented as units per $\mathrm{mL}$ of cell lysate. One unit of MPO activity was defined as that degrading 1 $\mu \mathrm{M}$ of peroxide per minute at $25^{\circ} \mathrm{C}$. Enzyme unit for MPO was determined using the formula: $U=(O D x$ $4 \times \mathrm{Vt} \times$ dilution factor)/ $\mathrm{L} \times € 460 \times \mathrm{t} \times \mathrm{Vs}$. (OD $=$ optical density, $\mathrm{Vt}=$ total volume in $\mathrm{ml}, \mathrm{L}$ is light path in $\mathrm{cm}, € 460=$ extinction coefficient of tetraguaiacol, $\mathrm{t}=$ the time of measurement in minutes and $\mathrm{Vs}=$ sample volume in $\mathrm{ml}$.)

\section{Statistical Analysis}

The values were three independent experiments and were expressed as mean \pm standard deviation (S.D.) for $\mathrm{n}$ determinations where $\mathrm{n}=3$ unless otherwise stated. Data analyses were performed using Sigma Plot version 12.5. The significance of differences from the respective controls was tested using one way ANOVA for each set of experiments.

\section{Results and Discussion}

The crude methanolic extracts of $H$. musciformis, $K$. alvarezii and G. dura were purified by silica gel column chromatography. Each fraction was eluted using petroleum ether and ethyl acetate solvent combinations. The fraction eluted using 95:5 solvent combinations of $H$. musciformis, 50:50 solvent combinations of $K$. alvarezii and 90:10 of $G$. dura showed significant amount of terpenoids. The fractions eluted by column chromatography were subjected to thin layer chromatography for confirming the presence of terpenoids. Parallelly, they were fractionated by GC-MS. Retention time and the relative abundance of each compound were recognized by GC-MS. The analysis of the 95:5 purified fraction of $H$. musciformis revealed the presence of 8 major peaks of terpenoids compatible with their fragmentation patterns (Fig:1). The 50:50 purified fraction of $K$. alvarezii showed 12 major peaks (Fig: 2) and 90:10 fraction of $G$. dura shows 4 major peaks of terpenoids (Fig: 3). The major terpenoids found in $H$. musciformis were Eicosane, Heneicosane, 2- Pentadecanone, Hexadecanoic acid, methyl ester, n-Hexadedcanoic acid, Hexadecanoic acid, ethyl ester, Heptadecanoic acid, methyl ester, 11- octadecanoic acid, methyl ester and in $K$. alvarezii were Eicosane, Heneicosane, Hexadecanoic acid, methyl ester, n-Hexadedcanoic acid and Beta amyrin whereas G. dura showed profound percentage of terpenoids such as Hexadecanoic acid methyl esters (15.58), n-Hexadedcanoic acid (80.78), 11- octadecanoic acid, methyl ester (80.78) and Phytol (3.65).

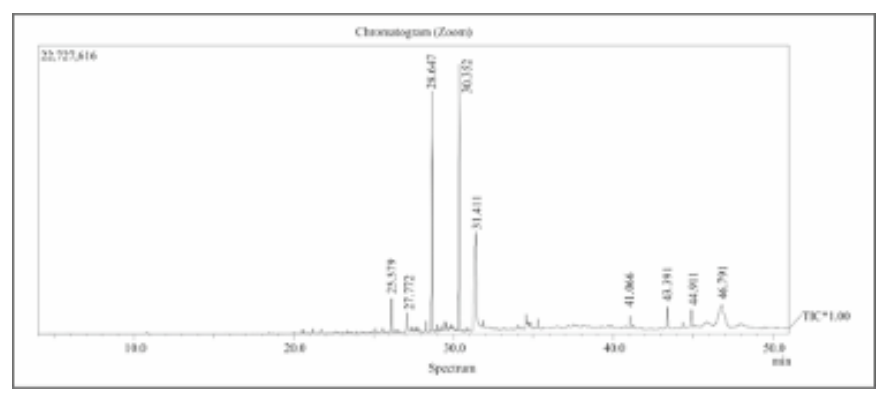

Fig. 1: GC- MS spectra showing terpenes composition of Hypnea musciformis

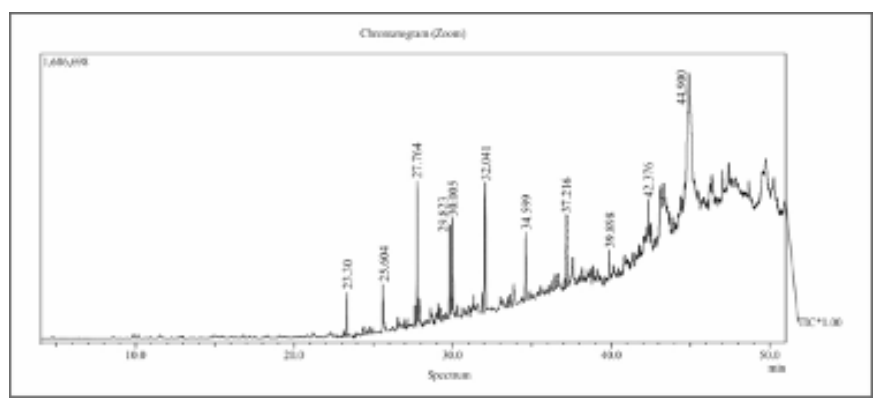

Fig. 2: GC-MS spectra showing terpenes composition of Kappaphycus alvarezii

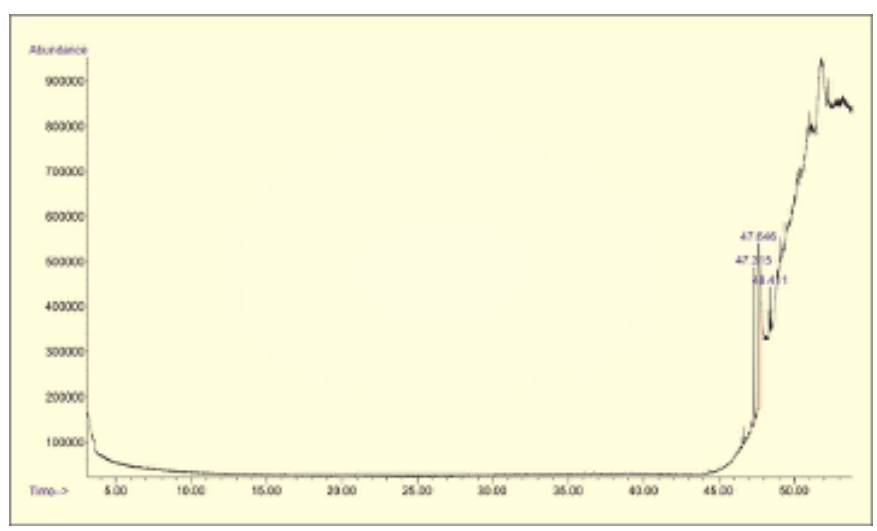

Fig.3: GC-MS spectra showing the terpenes composition of Gracilaria dura

\section{5-lipoxygenase (5-LOX) inhibitory activity}

The terpenoid extract from G. dura showed the highest 5-LOX inhibitory activity followed by $H$. musciformis and $K$. alvarezii. Based on the $\mathrm{IC}_{50}$ values, the extract of $G$. dura $\left(\mathrm{IC}_{50}=40.8 \mu \mathrm{g} / \mathrm{ml}\right)$ was considered as remarkable in terms of 5-LOX inhibitory activity followed by $H$. musciformis $\left(\mathrm{IC}_{50}=89.3 \mu \mathrm{g} / \mathrm{ml}\right)$ and $K$. alvarezii $\left(\mathrm{IC}_{50}=100 \mu \mathrm{g} / \mathrm{ml}\right)$ (Fig. 4). The activities of the extracts were comparable with the positive control indomethacin, which also showed a dose dependent activity against 5-LOX enzyme inhibitory activity. The $\mathrm{IC}_{50}$ value was significant i.e., $19.3 \mu \mathrm{g} / \mathrm{ml}$. 


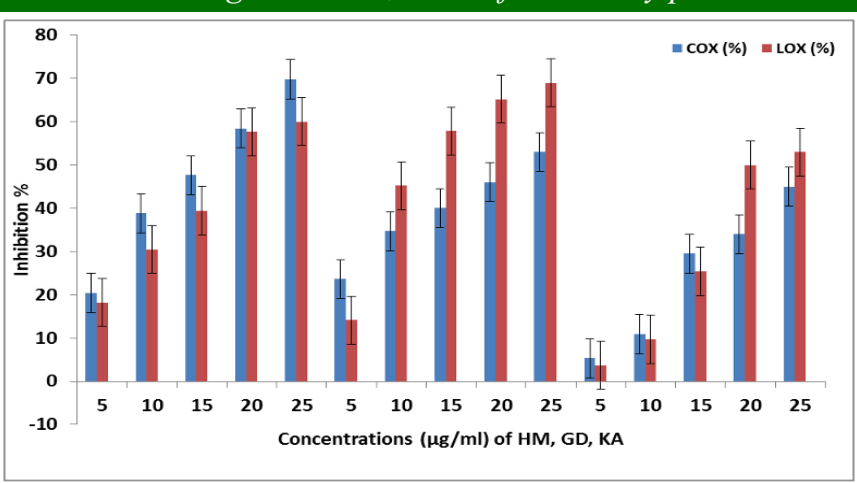

Fig.4: Terpenoid extracts from red algae on COX and LOX inhibitory activities

5- LOX is the first indexed enzyme involved in the arachidonic acid pathway leads to produce leukotrienes. Expression of 5-LOX has been connected with asthma, respiratory disorders, inflammatory bowel issues, cancer, cardiovascular disorders, atherosclerosis and stroke. Thus, LOX inhibitors are prompted as promising molecules for the treatment of inflammatory disorders on the basis of their roles in LOX pathways. Azad et al., proved that Premna integrifolia extracts as dual inhibitors of COX-2/5-LOX and thereby effective against inflammation and also as immune modulators (12). Sibata et al., reported inhibitory effects of brown algal phlorotannins on phospholipase A2s, lipoxygenases and cyclooxygenases. Inhibitors of these enzymes could become leading compounds in the development of new nonsteroidal anti-inflammatory drugs (13). Phycocyanin, a biliprotein isolated from Spirulina platensis significantly inhibited COX-2 with an $\mathrm{IC}_{50}$ value of 80 $\mathrm{nM}$. The anti-inflammatory activity of phycocyanin might be due to its selective COX-2 inhibitory effect, coupled with its efficiency in scavenging free radicals and inhibit lipid peroxidation (14). Antony and Chakraborty were first isolated the antioxidant abeolabdane type diterpenoid from intertidal red seaweed Gracilaria salicornia with 5- lipoxygenase inhibitory potential. They showed significantly greater activities against pro-inflammatory 5-lipoxygenase ( $\mathrm{IC}_{50} 0.86 \mathrm{mg} /$ $\mathrm{mL})$ than non-steroidal anti-inflammatory agent ibuprofen $\left(\mathrm{IC}_{50} 0.92 \mathrm{mg} / \mathrm{mL}, \mathrm{P}<0.05\right)(15)$.

\section{COX inhibitory activity}

Subsequently, the purified terpenoid extracts from $H$. musciformis, $G$. dura and $K$. alvarezii were screened for its effect on COX inhibitory activity. All purified terpenoid extracts of red algae were used as per the methodology to study the effect on the activity of COX and the results were showed in the fig 4. $H$. musciformis extracts showed a potent significant inhibition on the COX enzyme and was comparable with the positive control, indomethacin and results were expressed as percent inhibition of activity. G. dura revealed moderate activity but higher than $K$. alvarezii. The $\mathrm{IC}_{50}$ values were 74.2 (H. musciformis), 110.3 (G. dura) and $133.4 \mu \mathrm{g} / \mathrm{ml}$ (K. alvarezii).

Macrophages play leading roles in inflammatory disorders that are linked with up regulation of many inflammatory mediators. Further, PGE2 production is controlled by COX enzyme activity (16). Jiang et al., proved that $\gamma$-tocopherol is potential to inhibit COX activity and there by PGE2 production in macrophages and epithelial cells (17). The present results also showed that terpenoids inhibited COX enzyme activity effectively in a in a concentration dependent manner. Manju et al., reviewed the ideal and safer antiinflammatory treatment via dual COX-2/5-LOX inhibition (18). Similarly, a new morpholine alkaloid was isolated from the thalli of red seaweed Gracilaria opuntia showed greater cyclooxygenase-2 (COX-2) inhibitory activity ( $\mathrm{IC}_{50} 0.84 \mathrm{mg} / \mathrm{mL}$ ) in conjunction with in vitro 5-lipoxidase inhibitory activity ( $\mathrm{IC}_{50} 0.85 \mathrm{mg} /$ $\mathrm{mL}$ ) than non-steroidal anti-inflammatory drugs (19). A comparative study of in vitro anti-inflammatory activity of the sulphated polygalactan from two seaweeds $K$. alvarezii and $G$. opuntia was also reported (20). $G$. opuntia polygalactan exhibited greater COX-1 and COX-2 as well as 5-LOX inhibitory activity $(0.24 \mathrm{mg} /$ $\mathrm{mL}$ ) than that of $K$. alvarezii. The sulphated polygalactan isolated showed greater anti-inflammatory activity in comparison with the positive control aspirin. Maneesh et al., reported that the ethylacetate : methanol fraction of Sargassum wightii exhibited significantly greater in vitro anti-inflammatory properties as determined by COX-1 and COX-2 inhibitory activities than those extracted by $\mathrm{CHCl}_{3}$ and synthetic drug aspirin. It is significant to note that fraction of $S$. wightii also exhibited greater 5-LOX inhibitory activity than aspirin (21).

\section{Hyaluronidase inhibitory activity}

The hyaluronidase inhibitory activities of purified terpenoid extracts from $H$. musciformis, G. dura and $K$. alvarezii were ranged from 9.8 to $58.6 \%$. The $H$. musciformis extracts showed the highest activities followed by the extracts of $G$. dura and $K$. alvarezii (Fig.5). These two red algal extracts showed moderate to poor activities compared to the tannic acid $(69.88 \%, 500$ $\mu \mathrm{g} / \mathrm{mL}$ ) the synthetic drug used against inflammatory disorders.

Hyaluronidase (HA) hydrolyzes glycosaminoglycans including hyaluronan in the extracellular matrix during tissue remodeling process. Enhancement of HA activity was noticed in acute and chronic inflammatory diseases. Increased HA activity leads to degenerative changes in connective tissues. The cells, enzymes, and signaling modulators involved in these changes may be the targets for designinig compounds as dietary, pharmaceutical, and nutraceutical. The obtained results showed that purified terpenoid extracts have the potential to inhibit HA, which could regulate inflammation. Further, hyaluronidase triggers angiogenesis and facilitates tumor invasiveness. Sri Lankan medicinal plants were screened by Liyanaarachchim et al., to isolate novel cosmeceuticals i.e., the phytochemicals capable of inhibiting tyrosinase, elastase, hyaluronidase and promote antioxidant activities (22). Many studies have reported that HAase inhibition activity is a measure of anti-inflammatory potential of compounds. For example, caffeic acid oligomers from Clinopodium gracile, phlorotannins of 
brown algae, pentacyclic triterpenoids from Prismatomeris tetrandra (23).The polyphenol extracts of five red algae including Laminaria japonica, Porphyra sp., Spirulina platensis, Chlorella pyrenoidosa and Scytosiphon sp. were analyzed for its antiallergic activity with the hyaluronidase inhibition assay (23). The antiallergic activity of Scytosiphon sp. extract was even higher than the typical anti-allergic drug Disodium cromoglycate (DSCG). A number of studies have reported that polysaccharides have hyaluronidaseinhibitory effects. The hyaluronidase-inhibitory activity of a polysaccharide was proved from the unicellular marine alga Porphyridium purpureum (24). Six antiallergic phlorotannins from the brown alga Eisenia arborea were examined for their inhibitory effects on hyaluronidase activities. Eckol inhibited the hyaluronidase activity similar to the typical inhibitors, EGCg and disodium cromoglycate. The other five phlorotannins also inhibited the enzyme activity stronger than the above inhibitors (25).

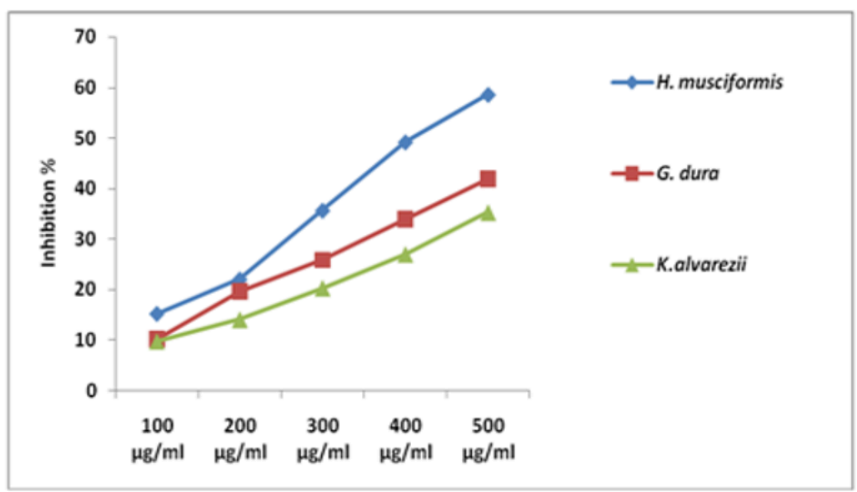

Fig. 5: Terpenoid extracts from red algae on Hyaluronidase inhibitory activity

Xanthine oxidase (XO) inhibitory activity

The purified terpenoid extracts from $H$. musciformis, G. dura and $K$. alvarezii showed varied inhibitory activities against xanthine oxidase enzyme and activities ranged from 7.4 to $62.1 \%$. The results revealed that, the terpenoid extracts from $H$. musciformis had the highest inhibitory activity followed by the extracts of $G$. dura and $K$. alvarezii (Fig.6) with respect to the reference standard allopurinol. The extract of $H$. musciformis, which showed the highest xanthine oxidase inhibitory activity in a dose dependent inhibitions within the concentration range of $50-250 \mu \mathrm{g} / \mathrm{mL}$ with a $\mathrm{IC}_{50}$ value of $208.5 \mu \mathrm{g} / \mathrm{mL}$ (Fig 6; Allopurinol: $\mathrm{IC}_{50}: 5.2 \pm$ $0.01 \mu \mathrm{g} / \mathrm{mL}$ ).

Inhibition of XO down regulates the uric acid synthesis which is related to primary or secondary gout issues. The application of phytochemicals useful for the management of gouty arthritic diseases are those which can inhibit xanthine oxidase and the generation of ROSs and the resulting inflammatory reactions linked with the accumulation of uric acid crystals in the joints and kidneys (26). Similarly, Djarmouni et al., established the role of xanthine oxidase inhibitory activities of Santolina chamaecyparissus in anti-inflammatory events (27). In vitro and in vivo xanthine oxidase (XO) inhibitory and antihyperuricemic activities of Quercus acuta by the active phytochemicals from the leaf extract (28). In vivo study using hyperuricemic mice induced with potassium oxonate demonstrated that the $Q$. acuta could inhibit hepatic $\mathrm{XO}$ activity at a relatively low oral dose $(50 \mathrm{mg} / \mathrm{kg})$ and significantly alleviate hyperuricemia to a similar extent as allopurinol. Trabsa et al., reported the kinetics of inhibition of xanthine oxidase by Lycium arabicum and its protective effect against oxonate induced hyper uricemia and renal dysfunction in mice (29). The extracts of Paronychia argentea were effective in both XO inhibiting and superoxide radical scavenging was evaluated by Moufida and Meriem (30). They established that these plant extracts can be used as a source of bioactive compounds useful as natural antioxidants and therapeutic agents for hyperuricemia, gout and other related diseases, where inhibition of $\mathrm{XO}$ and scavenging of superoxide radicals are necessary.

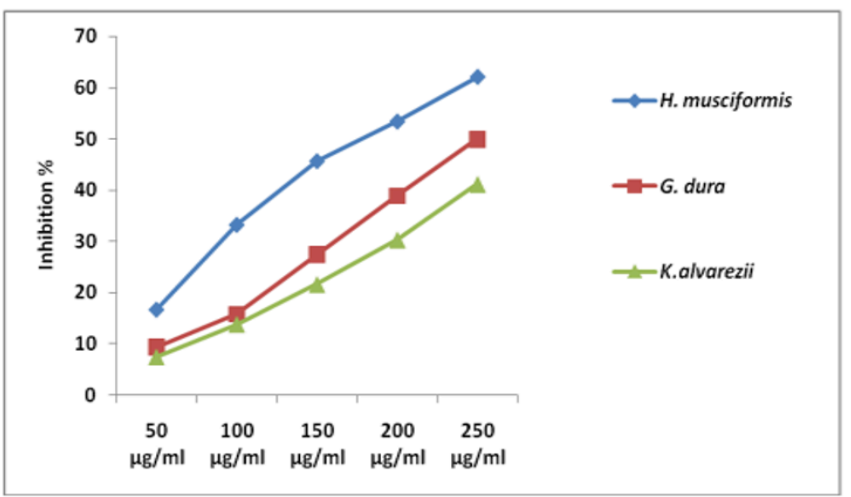

Fig.6: Terpenoid extracts from red algae on Xanthine oxidase inhibitory activity

\section{Viability of LPS-activated RAW 264.7 macrophages}

The purified terpenoid extracts from $H$. musciformis, G. dura and $K$. alvarezii showed high viability rate among RAW 264.7 macrophages (Cell viability $>90 \%)$ at the tested concentrations and there by suggesting non cytotoxicity of the terpenoid extracts from the red algae (Fig.7). This may be the reason for searching novel phytochemicals from plant based products.

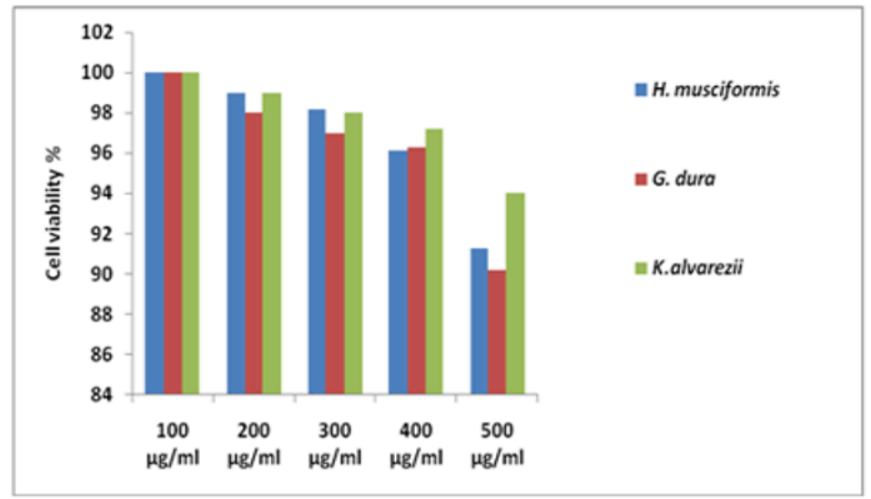


Murugan K et.al., Anti-inflammatory potentialities of purified terpenoid extracts from the selected sea weeds

Fig.7: Terpenoid extracts from red algae on cell viability of RAW-264.7 macrophages

Kim et al., (31) evaluated the antiinflammatory properties of Stauntonia hexaphylla fruit extract in LPS activated RAW-264.7 macrophages and revealed the safety of plant extracts in terms of viability in murine cell lines. Potential of Anredrea cordifolia and Piper crocatum extracts were observed through inflammatory markers such as TNF- $\alpha$, IL-1, IL-6, and NO inhibitory activity assays in LPS induced macrophage cell line (RAW 264.7). Both $A$. cordifolia and $P$. crocatum extracts decreased TNF- $\alpha$ level in LPS-induced RAW 264.7, which was comparable to normal cell (32). Tseng et al., reported a major flavonoid component from Morus australis named morusin. M. australis extract together with morusin inhibited lipopolysaccharide-induced production of nitrite and prostaglandin E2 in RAW
264.7 cells (33). Inhibition of lipopolysaccharide induced inflammatory responses by Sargassum hemiphyllum sulfated polysaccharide extract in raw 264.7 macrophage cells was proven by Hwang et al., (34). The secretion profiles of proinflammatory cytokines were found to significantly reduce in a dose dependent manner.

\section{Nitric oxide (NO) production inhibitory activity}

The nitric oxide inhibitory activities of purified terpenoid extracts from $H$. musciformis, $G$. dura and $K$. alvarezii were high to moderate in comparison to the reference standard L-NMMA and ranged from $4.9 \%$ to $64.7 \%$. Of the tested terpenoid extracts, the extract of $H$. musciformis showed significant nitric oxide inhibitory activity, while that of $G$. dura and $K$. alvarezii showed moderate activities (Table 1).

Table 1: Production of NO $(\mu \mathrm{M})$ and percentage of NO inhibition by terpenoid extracts from red algae

\begin{tabular}{|c|c|c|c|c|c|c|}
\hline & \multicolumn{2}{|c|}{ H. musciformis } & \multicolumn{2}{|c|}{ G. dura } & \multicolumn{2}{|c|}{ K. alvarezii } \\
\hline Concentration & $\begin{array}{c}\text { NO } \\
(\mu \mathrm{M})\end{array}$ & $\begin{array}{c}\text { NO } \\
\text { Inhibition (\%) }\end{array}$ & $\begin{array}{c}\text { NO } \\
(\mu \mathrm{M})\end{array}$ & $\begin{array}{c}\text { NO } \\
\text { Inhibition (\%) }\end{array}$ & $\begin{array}{c}\text { NO } \\
(\mu \mathrm{M})\end{array}$ & $\begin{array}{c}\text { NO } \\
\text { Inhibition (\%) }\end{array}$ \\
\hline $25 \mu \mathrm{g} / \mathrm{ml}$ & 39.6 & 10.2 & 42 & 7.5 & 46 & 4.9 \\
\hline $50 \mu \mathrm{g} / \mathrm{ml}$ & 28.3 & 18.6 & 30.6 & 14 & 35.5 & 10.2 \\
\hline $75 \mu \mathrm{g} / \mathrm{ml}$ & 21 & 24 & 25.3 & 29.4 & 30 & 24.7 \\
\hline $100 \mu \mathrm{g} / \mathrm{ml}$ & 14 & 50 & 19.5 & 40.3 & 24 & 29.87 \\
\hline $200 \mu \mathrm{g} / \mathrm{ml}$ & 8.5 & 64.7 & 11 & 50 & 13 & 40 \\
\hline
\end{tabular}

NO: Nitric Oxide

Over production of nitric oxide is linked with many life style disorders such as arthritis, diabetes, and stroke, autoimmune and chronic inflammation. Similarly, pathogen infections also induce neurodegenerative disorders via the synthesis of nitric oxide. Inducible nitric oxide synthase (iNOS) triggers NO synthesis which in turn leads to vasodilation and hypotension noticed among septic shock and inflammation diseases. Therefore, NO inhibitors are lead molecules for the treatment of inflammatory issues.

For example, thyme oleoresin effectively inhibits NO production and iNOs gene expression in RAW 264.7 murine cells (35). Similarly, Gutierrez and Hoyo-Vadillo confirmed that the extracts of Petiveria alliacea in regulating NO synthesis and thereby anti-inflammatory disorders (36). Inhibitory activity of nitric oxide production by hirsutane-type sesquiterpenes was noticed from the red alga derived fungus Chondrostereum was also reported (37).

Neorogioltriol, a tricyclic brominated diterpenoid isolated from the organic extract of the red algae
Laurencia glandulifera, showed anti-inflammatory effects under in vitro condition in LPS-treated RAW 264.7 macrophages, and also in vivo using the carrageenan-induced paw edema model (38). In addition, anti-inflammatory effects of lipid extract of Tetraselmis chuii, Chlorella sorokiniana and Chondrus crispus in RAW 264.7 macrophages (39).

\section{Myeloperoxidase (MPO) activity}

The purified terpenoid extracts from $H$. musciformis, G. dura and K. alvarezii were effective in inhibiting myeloperoxidase (MPO). A concentration dependent increase in the inhibition of myeloperoxidase activity was exhibited by the terpenoid extracts. At higher concentrations inhibitory effect was significantly high. $H$. musciformis showed excellent MPO inhibition suggesting the ideal anti-inflammatory activity of the same. MPO inhibition at $100 \mu \mathrm{g} / \mathrm{ml}$ terpenoid extracts from $H$. musciformis $(0.0083)$ was comparable with that of the standard drug indomethacin (0.0058) (Table 2).

Table 2. Effect of terpenoid extracts from red algae on Myeloperoxidase activity $(\mu \mathrm{g} / \mathrm{mL})$

\begin{tabular}{|c|c|c|c|}
\hline Conc. & H. musciformis & G. dura & K. alvarezii \\
$12.5 \mu \mathrm{gg} / \mathrm{ml}$ & 0.0144 & 0.0166 & 0.0197 \\
$25 \mu \mathrm{g} / \mathrm{ml}$ & 0.0140 & 0.0159 & 0.0192 \\
$50 \mu \mathrm{g} / \mathrm{ml}$ & 0.0137 & 0.0147 & 0.0178 \\
$75 \mu \mathrm{g} / \mathrm{ml}$ & 0.0131 & 0.0137 & 0.0161 \\
$100 \mu \mathrm{g} / \mathrm{ml}$ & 0.0083 & 0.0098 & 0.0103
\end{tabular}


In the inflammatory reactions, oxidative stress is triggered by phagocytes containing myeloperoxidase, and these uplift ROS synthesis and down regulates oxidative defense. As an important indicator of neutrophil leaching, myeloperoxidase activity should be regulated during treatments. The protective effect of the terpenoid extracts in the present study was through balancing oxidative stress via inhibiting the MPO synthesis in the murine cells. Chniguir et al., revealed that Syzygium aromaticum aqueous extract inhibits myeloperoxidase and protects mice from LPS-induced lung inflammation (40). Inhibition of myeloperoxidase and neutrophil mediated hypochlorous acid formation in vitro and endothelial cell injury by epigallocatechin gallate was also reported (41). Further, the antiinflammatory activity of a lectin extracted from the red seaweed Bryothamnion triquetrum by means of inhibiting myeloperoxidase activity in paw tissue (42). Similarly, inhibitive effect of quercetin on MPO mediated oxidant hypochlorous acid formation or scavenging of the oxidant hypochlorous acid was also evaluated (43).

\section{Conclusion}

Synthetic drugs such as steroidal and nonsteroidal have been employed for the management of inflammatory diseases. Due to high costs and adverse effects, there is a profound interest in plant based research to identify novel agents which may be cheaper and have no side effect. The present study revealed that the purified terpenoid extracts from $H$. musciformis exhibited potent antiinflammatory activities via regulating the enzymes such as COX, LOX, HA, XO, MPO and also by inhibiting NO synthesis. Therefore, the usage of many of these algae by locals as folk medicine is justifiable. This sort of research provides data to develop new drugs for future use.

\section{References}

1. Rocha D.H.A, Seca A.M.L, Diana C.G.A, Seaweed Secondary Metabolites In Vitro And In Vivo Anticancer Activity. Mar Drugs. 2018; 16(11); 410-416. doi: 10.3390/md16110410.

2. Wells M.L, Potin P, Craigie J.S, Raven J.A, Merchant S.S, Algae As Nutritional And Functional Food Sources: Revisiting Our Understanding. J Appl Phycol. 2017; 29(2);949982. doi: 10.1007/s10811-016-0974-5.

3. Mansuya P, Aruna P, Sridhar S, Kumar J.S, Babu S, Antibacterial Activity And Qualitative Phytochemical Analysis Of Selected Seaweeds From Gulf Of Mannar Region. J of Exp Sci. 2010; 1(8);23-26.

4. Sahani K, Thakur D, GC MS Analysis Of Endophytic Fungi Curvularia Aeria Mtcc-12847 Isolated From Tribulus terrestris L. Int $\mathrm{J}$ of Pharma and Pharmaceutical Sci. 2019; 11 ( 4$) ; 26-32$. do i : $10.22159 /$ ijpps.2019v11i4.28440.
5. Abueid L, Uslu U, Cumbul A, Ogunc A.V, Ercan F, Alican I, Inhibition Of 5-Lipoxygenase By Zileuton In A Rat Model Of Myocardial Infarction. Anatol J Cardiol. 2017; 17(4); 269275. doi: 10.14744/AnatolJCardiol.2016.7248.

6. Jacob J, Kumar P.B, Dual COX/LOX Inhibition: Screening And Evaluation Of Effect Of Medicinal Plants Of Kerala As Antiinflammatory Agents. J of Pharma Phytochem. 2015; 3(6); 62-66.

7. Sahasrabudhe A, Dedhar M, Anti-Hyaluronidase, Anti-Elastase Activity Of Garcinia indica. Int $\mathrm{J}$ Bot. 2010; 6(3); 299-303. doi: 10.3923/ ijb.2010.299.303.

8. Duong N.T, Vinh P.D, Thuong P.T, Hoai N.T, Thanh L.N, Bach T.T, Nam N.H, Anh N.H, Xanthine Oxidase Inhibitors From Archidendron clypearia (Jack.) I.C. Nielsen: Results From Systematic Screening Of Vietnamese Medicinal Plants. Asian Pac J Trop Med. 2017; 10(6); 549556. doi: 10.1016/j.apjtm.2017.06.002.

9. Min H.Y, Kim M.S, Jang D.S, Park E.J, Seo E.K, Lee S.K, Suppression Of LipopolysaccharideStimulated Inducible Nitric Oxide Synthase (Inos) Expression By A Novel Humulene Derivative In Macrophage Cells. Int Immunopharmacol. 2009; 9(7-8); 844-49. doi: 10.1016/j.intimp.2009.03.005.

10. Cheenpracha S, Park E.J, Rostama B, Pezzuto J.M, Chang L.C, Inhibition Of Nitric Oxide (NO) Production In Lipopolysaccharide (LPS)Activated Murine Macrophage RAW 264.7 Cells By The Norsesterterpene Peroxide, Epimuqubilin A. Mar Drugs. 2010; 8(3); 429-37. doi: 10.3390/ md8030429.

11. Yang E.J, Yim E.Y, Song G, Kim G.O, Hyun C.G, Inhibition Of Nitric Oxide Production In Lipopolysaccharide-Activated RAW 264.7 Macrophages By Jeju Plant Extracts. Interdiscip Toxicol. 2009; 2(4); 245-249. doi: 10.2478/ v10102-009-0022-2.

12. Deepa J, Aleykutty N.A, Jyoti H, Comparative Evaluation Of In Vitro Antiinflammatory Activity Of Psidium guajava And Syzygium cumini Leaves. Int J Ayur Pharma Res. 2017; 5(10); 33-41.

13. Azad R, Babu N.K, Gupta A.D, Reddanna P, Evaluation Of Anti-Inflammatory And Immunomodulatory Effects Of Premna integrifolia Extracts And Assay-Guided Isolation Of A COX-2/5-LOX Dual Inhibitor. Fitoterapia. $2018 ; 131 ; 189-199$. doi: $10.1016 /$ j.fitote.2018.10.016.

14. Shibata T, Nagayama K, Tanaka R, Yamaguchi $\mathrm{K}$, Nakamura T, Inhibitory Effects Of Brown Algal Phlorotannins On Secretory Phospholipase A2s, Lipoxygenases And Cyclooxygenases. J of Appl Phyc. 2003; 15(1); 61-66. doi: 10.1023/ A:1022972221002.

15. Antony T, Chakraborty K, First Report Of Antioxidant Abeo-Labdane Type Diterpenoid From Intertidal Red Seaweed Gracilaria 
salicornia With 5-Lipoxygenase Inhibitory Potential. Nat Prod Res. 2018; 32; 1150-1160. doi:10.1080/14786419.2018.1508150.

16. Beharka A.A, Wu D, Serafini M, Meydani S.N, Mechanism Of Vitamin E Inhibition Of Cyclooxygenase Activity In Macrophages From Old Mice: Role Of Peroxynitrite. Free Radic Biol Med. 2002; 32(6); 503-511. doi: 10.1016/ s0891-5849(01)00817-6.

17. Jiang Q, Elson-Schwab I, Courtemanche C, Ames B.N, Gamma-Tocopherol And Its Major Metabolite, In Contrast To Alpha-Tocopherol, Inhibit Cyclooxygenase Activity In Macrophages And Epithelial Cells. Proc Natl Acad Sci USA. 2000; 97(21); 11494-11499. doi: 10.1073/ pnas.200357097.

18. Manju S.L, Ethiraj K.R, Elias G, Jacob P.J, Safer Anti-Inflammatory Therapy Through Dual COX-2/5-LOX Inhibitors: A Structure-Based Approach. Eur J Pharm Sci. 2018; 121; 356-381. doi: 10.1016/j.ejps.2018.06.003.

19. Makkar F, Chakraborty K, Previously Undescribed Antioxidative Azocinyl Morpholinone Alkaloid From Red Seaweed Gracilaria opuntia With Anti-Cyclooxygenase And Lipoxygenase Properties. Nat Prod Res. 2018 ; 32( 10$)$; $1150-60$. do i : 10.1080/14786419.2017.1326041.

20. Makkar F, Chakraborty K, Antidiabetic And Antiinflammatory Potential of Sulphated Polygalactans From Red Seaweeds Kappaphycus alvarezii and Gracilaria opuntia. Int $\mathbf{J}$ of Food Pro. 2017 ; 20(6); $1326-37$. doi : 10.1080/10942912.2016.1209216.

21. Maneesh A, Makkar F, Chakraborty K, Pharmacological Activities Of Brown Seaweed Sargassum wightii (Family Sargassaceae) Using Different In Vitro Models. Int J of Food Prop. 2017 ; $20(4)$; $931-945$. doi : $10.1080 / 10942912.2016 .1189434$

22. Liyanaarachchi G.D, Samarasekera J.K.R.R, Mahanama K.R.R, Hemalal K.D.P, Tyrosinase, Elastase, Hyaluronidase, Inhibitory And Antioxidant Activity Of Sri Lankan Medicinal Plants For Novel Cosmeceuticals. Indust Crops Pro. 2018; 111; 597-605. doi: 10.1016/ j.indcrop.2017.11.019.

23. Chen Y, Lin H, Li Z, Mou Q, The Antiallergic Activity of Polyphenol Extracted From Five Marine Algae. J Ocean Univ of China. 2015; 14 (4); $681-684$. do i : 10.1007 / s11802-015-2601-5.

24. Mase T, Yamauchi M, Kato Y, Esaki H, Isshiki S, Hyaluronidase-Inhibiting Acidic Polysaccharide Isolated From Porphyridium purpureum. 2013; 44; 105 - 113 .

25. Sugiura Y, Matsuda K, Yamada Y, Imai K, Kakinuma M, Amano H, Radical Scavenging And Hyaluronidase Inhibitory Activities of Phlorotannins From The Edible Brown Alga Eisenia arborea. Food Sci Technol Res. 2008; 14(6); 595 - 598. doi: 10.3136/fstr.14.595.
26. Mohapatra S, Kabiraj P, Agarwal T, Asthana S, Annamalai N, Arsad H, Siddiqui M.H, Khursheed A, Targeting Jatropha Derived Phytochemicals To Inhibit The Xanthine Oxidase \& Cyclooxygenase-2: In Silico Analysis Towards Gout Treatment. Int J Pharm Pharm Sci. 2015; 7(1); 360-363.

27. Djarmouni M, Baghiani A, Adjadj M, Arrar L, Anti-Inflammatory And Xanthine Oxidase Inhibition Activities Of Santolina chamaecyparissus Extracts. Annual Res Rev Biol. 2018; 229(6); 1-7. doi: 10.9734/ARRB/ 2018/39084.

28. Yoon I.S, Park D.H, Bae M.S, Oh D.S, Kwon N.H, Kim J.E, Choi C.Y, Cho S.S, In Vitro and In Vivo Studies on Quercus acuta Thunb. (Fagaceae) Extract: Active Constituents, Serum Uric Acid Suppression, and Xanthine Oxidase Inhibitory Activity. Evidence-Based Comp Alt Medi. $\quad 2017$; $8(2) ; \quad 112-18$. doi:10.1155/2017/4097195.

29. Trabsa H, Baghiani A, Boussoualim N, Krache I, Khennouf S, Charef N, Arrar L,Kinetics Of Inhibition Of Xanthine Oxidase By Lycium arabicum And Its Protective Effect Against Oxonate Induced Hyperuricemia And Renal Dysfunction In Mice. T J of Pharma Res. 2015; 14(2); 249-256. doi: 10.4314/tjpr.v14i2.9.

30. Moufida A, Meriem D, Study Of The Antioxidant Property And Xanthine Oxidase Inhibitory Activity Of Various Extracts From The Algerian Medicinal Plant Paronychia argentea L. Pharmacogn Commn, 2018; 8(1); 49-53. doi: 10.5530/pc.2018.1.9.

31. Kim J, Kim H, Choi H, Jo A, Kang H, Yun H, Im S, Choi C, Anti-Inflammatory Effects Of A Stauntonia hexaphylla Fruit Extract In Lipopolysaccharide-Activated Raw-264.7 Macrophages And Rats By Carrageenan-Induced Hind Paw Swelling.Nutri. 2018; 10(1); e110. doi: 10.3390/nu10010110.

32. Laksmitawati D.R, Widyastuti A, Karami N, Afifah E, Rihibiha D.D, Nufus H, Widowati W, Anti-inflammatory Effects of Anredera cordifolia and Piper crocatum Extracts On Lipopolysaccharide-Stimulated Macrophage Cell Line. Bangladesh J Pharmacol. 2017; 12(1);35-40. doi: 10.3329/bjp.v12i1.28714.

33. Tseng T.H, Lin W.L, Chang C.K, Lee K.C, Tung S.Y, Kuo H.C, Protective Effects Of Morus Root Extract (MRE) Against LipopolysaccharideActivated RAW 264.7 Cells And $\mathrm{Ccl}_{4}$-Induced Mouse Hepatic Damage. Cell Physiol Biochem. 2018; 51(3); 1376-88. doi: 10.1159/000495555.

34. Hwang P.A, Chien S.Y, Chan Y.L, Lu M.K, Wu C.H, Kong Z.L, Wu C.J, Inhibition of Lipopolysaccharide (LPS)-Induced Inflammatory Responses by Sargassum hemiphyllum Sulfated Polysaccharide Extract in RAW 264.7 Macrophage Cell. J Agric Food Chem. 2015; 59(5); 2062-68. doi: 10.1021/jf1043647. 
35. Mangal C.S, Anitha R, Lakshmi T, Inhibition Of Nitric Oxide Production And Nitric Oxide Synthase Gene Expression In LPS Activated RAW 264.7 Macrophages By Thyme Oleoresin From Thymus vulgarism. J Young Pharm. 2018; 10(4); 481-83. doi: 10.5530/jyp.2018.10.104.

36. Gutierrez R.M.P, Hoyo-Vadillo C, Antiinflammatory Potential of Petiveria alliacea on Activated RAW264.7 Murine Macrophages. Pharmacogn Mag.2017; 13(50); 174-8. doi: $10.4103 / \mathrm{pm} . \mathrm{pm} \_479$ 16.

37. Hsiao G, Chi W.C, Pang K.L, Chen J.J, Kuo Y.H, Wang Y.K, Cha H.J, Chou S.C, Lee T.H, Hirsutane-Type Sesquiterpenes With Inhibitory Activity Of Microglial Nitric Oxide Production From The Red Alga-Derived Fungus Chondrostereumsp. J Nat Prod.2017; 80(5); 1615-22. doi: 10.1021/acs.jnatprod.7b00196.

38. Ventura T.L.B, Silva Machado F.L, de Araujo M.H, de Souza Gestinari L.M, Kaiser C.R, Esteves F, Lasunskaia E.B, Soares A.R, Muzitano M.F, Nitric Oxide Production Inhibition And Anti-Mycobacterial Activity Of Extracts And Halogenated Sesquiterpenes From The Brazilian Red Alga Laurencia dendroidea J. Agardh. Pharmacogn Mag.2015; 11(44); 611618. doi: 10.4103/0973-1296.172972.

39. Robertson R.C, Guiheneuf F, Bahar B, Schmid M, Stengel D.B, Fitzgerald G.F, Ross R.P, Stanton C, The Anti-Inflammatory Effect Of Algae-Derived Lipid Extracts On
Lipopolysaccharide (LPS)-Stimulated Human THP-1 Macrophages. Mar drugs.2015; 13(8); 5402-24. doi: 10.3390/md13085402.

40. Chniguir A, Zioud F, Marzaioli V, El-Benna J, Bachoual R, Syzygium aromaticum Aqueous Extract Inhibits Human Neutrophils Myeloperoxidase And Protects Mice From LPSInduced Lung Inflammation. Pharma Bio.2019; $57(1)$; $56-64$ d o i : 10.1080/13880209.2018.1557697.

41. Tian R, Ding Y, Peng Y, Lu N,Inhibition Of Myeloperoxidase- And Neutrophil- Mediated Hypochlorous Acid Formation In Vitro And Endothelial Cell Injury By Epigallocatechin Gallate. J Agric Food Chem.2017; 65(15); 3198-203. doi:10.1021/acs.jafc.7b00631.

42. Fontenelle T.P.C, Lima G.C, Mesquita J.X, de Souza Lopes J.L, de Brito T.V, Junior F.C.V, Sales A.B, Aragao K.S, Souza M.H.L.P, Barbosa A.L.R, Freitas A.L.P, Lectin Obtained From The Red Seaweed Bryothamnion triquetrum: Secondary Structure And Anti-Inflammatory Activity In Mice. Int $\mathrm{J}$ Biol Macromol.2018; 112 ; $1122-1130$. do i : $10.1016 /$ j.ijbiomac.2018.02.058.

43. Lu N, Sui Y, Tian R, Peng Y.Y, Inhibitive Effects Of Quercetin On Myeloperoxidase-Dependent Hypochlorous Acid Formation And Vascular Endothelial Injury. J Agric Food Chem.2018; 66(19); 4933-40. doi: 10.1021/acs.jafc.8b01537. 